\title{
Extreme hypernatremia as a probable cause of fatal arrhythmia: a case report
}

\author{
Maulee Hiromi Arambewela*, Noel P. Somasundaram and Chaminda Garusinghe
}

\begin{abstract}
Background: Hypernatremia is a frequent occurrence among hospitalized patients. Severe hypernatremia is associated with mortality rates of over $60 \%$. Extreme hypernatremia, defined as sodium levels $>190 \mathrm{mmol} / \mathrm{l}$, is a rare occurrence. The literature on electrocardiographic changes occurring with this degree of hypernatremia is extremely scarce. We report the case of an 11-year-old Sri Lankan girl who presented with sodium levels of 226 $\mathrm{mmol} / \mathrm{l}$ following infusion with $3 \%$ hypertonic saline who developed diffuse QT prolongation leading to fatal ventricular tachycardia.

Case presentation: An 11-year-old Sri Lankan girl presented with fever, headache, vomiting, and altered level of consciousness. Following admission she developed generalized tonic-clonic seizures and was intubated and ventilated. She had a recent history of polyuria and polydipsia. Magnetic resonance imaging of her brain revealed hydrocephalus due to possible craniopharyngioma. A ventriculoperitoneal shunt was inserted and she was infused with $3 \%$ hypertonic saline in an attempt to reduce intracranial pressure. The following day she became polyuric and dehydrated with tachycardia and low blood pressure. Biochemistry revealed serum sodium of $226 \mathrm{mmol} / \mathrm{l}$, measured serum osmolality of $470 \mathrm{mOsm} / \mathrm{kg}$, urine osmolality of $280 \mathrm{mOsm} / \mathrm{kg}$, urine spot sodium of $116 \mathrm{mmol} / \mathrm{l}$, blood urea of $8.1 \mathrm{mmol} / \mathrm{l}$, and blood glucose of $8.5 \mathrm{mmol} / \mathrm{l}$. Her serum potassium, calcium, and magnesium levels were normal. Extreme hypernatremia due to infusion of $3 \%$ hypertonic saline in the background of cranial diabetes insipidus was considered. She was managed aggressively with $5 \%$ dextrose infusion and clear water via nasogastric feeding to correct the fluid deficit of 7 liters over 36 hours. Her sodium levels dropped to $160 \mathrm{mmol} / \mathrm{l}$ the following day. However, she developed electrocardiographic changes with widespread gross QT prolongation with ST segment deviations followed by fatal ventricular tachycardia.

Conclusions: Extreme hypernatremia is rare, and the literature on electrocardiographic changes occurring at such high levels of sodium is scarce. At present there are no established guidelines on rate and mode of correction of such high sodium levels. This case highlights the electrocardiographic changes observed during extreme hypernatremia, controversies in managing increased intracranial pressure with hypertonic saline, and dilemmas encountered in managing extreme hypernatremia.
\end{abstract}

Keywords: Extreme hypernatremia, ECG changes, Hypertonic saline, Elevated intracranial pressure, Case report

\section{Background}

Hypernatremia is a frequent electrolyte abnormality observed in hospitalized patients. It is most frequently caused by excess water loss and less frequently by increased sodium intake. Severe hypernatremia $(>160$ $\mathrm{mmol} / \mathrm{l})$ is a serious condition associated with high mortality of $>60 \%$ [1]. Cases reported on extreme hypernatremia $(>190 \mathrm{mmol} / \mathrm{l})$ are few and literature on

\footnotetext{
* Correspondence: Maulee_80@yahoo.com

Department of Diabetes and Endocrinology, National Hospital of Sri Lanka, Colombo, Sri Lanka
}

(c) 2016 The Author(s). Open Access This article is distributed under the terms of the Creative Commons Attribution 4.0 International License (http://creativecommons.org/licenses/by/4.0/), which permits unrestricted use, distribution, and reproduction in any medium, provided you give appropriate credit to the original author(s) and the source, provide a link to the Creative Commons license, and indicate if changes were made. The Creative Commons Public Domain Dedication waiver (http://creativecommons.org/publicdomain/zero/1.0/) applies to the data made available in this article, unless otherwise stated. degree of hypernatremia are scarce. Current literature on the management of hypernatremia recommends slow correction in chronic hypernatremia with a 10 to 12 $\mathrm{mmol} / \mathrm{l}$ reduction in order to prevent adverse neurological sequelae such as cerebral edema [2]. However, there are many controversies in the rate of correction in patients with extreme hypernatremia as persistent hypernatremia is associated with high mortality [3]. Management in such extreme cases poses a therapeutic 
challenge with some patients achieving successful outcomes with fluid therapy and others with dialysis.

We report the case of a girl with sodium levels of 226 $\mathrm{mmol} / \mathrm{l}$ following infusion with $3 \%$ hypertonic saline in an attempt to reduce intracranial pressure who developed ECG changes of diffuse QT prolongation and ST segment deviations leading to fatal ventricular tachycardia (VT).

\section{Case presentation}

An 11-year-old Sri Lankan girl presented with a 2-day history of fever, headache, vomiting, and altered level of consciousness. She had been experiencing polyuria and polydipsia during the past 2 weeks. There was no history of chronic headaches, visual disturbances, respiratory symptoms, or abdominal symptoms. She was not known to be diabetic. An examination revealed an unwelllooking febrile girl. Her height was $140 \mathrm{~cm}$ (25th centile) and her weight was $25 \mathrm{~kg}$ (3rd centile). There was no evidence of neck stiffness or positive Kernig's sign. Following admission she developed generalized tonicclonic seizures which required intubation and ventilation. Random blood glucose and electrolyte panel including sodium, potassium, calcium, and magnesium were normal. She was empirically started on antibiotics administered intravenously for possible meningitis. Magnetic resonance imaging revealed gross hydrocephalus with suprasellar mass most likely due to craniopharyngioma (Figs. 1, 2, and 3). A ventriculoperitoneal shunt was inserted and she was started on $3 \%$ hypertonic saline to reduce intracranial pressure. Her basal serum sodium levels were $140 \mathrm{mmol} / \mathrm{l}$ and she was commenced on a dose of $5 \mathrm{ml} / \mathrm{kg} 8$ hourly, aiming to increase her sodium levels to 160 to $170 \mathrm{mmol} / \mathrm{l}$. Her serum electrolytes were monitored 8 hourly. Her sodium levels rose to $163 \mathrm{mmol} / \mathrm{l}$ after the first 24 hours. It was decided to repeat another dose of $3 \%$ hypertonic saline. However, during the latter part of the day she became polyuric and dehydrated. Her blood pressure was $80 / 60$ and pulse rate was 130 beats per minute. She was hydrated with boluses of normal saline and commenced on hydrocortisone replacement administered intravenously. As her blood pressure failed to stabilize she was started on inotropic support with noradrenaline and dobutamine infusions. Her serum sodium levels were $226 \mathrm{mmol} / \mathrm{l}$ and further doses of $3 \%$ hypertonic saline were stopped immediately. Other biochemical investigations were as follows: serum potassium $3.8 \mathrm{mmol} / \mathrm{l}$ ( 3.5 to $5.0 \mathrm{mmol} / \mathrm{l}$ ), blood urea $8.1 \mathrm{mmol} / \mathrm{l}$ ( 2.5 to $8.0 \mathrm{mmol} / \mathrm{l})$, serum creatinine $76 \mu \mathrm{mol} / \mathrm{l}$ (70 to $120 \mu \mathrm{mol} / \mathrm{l}$ ), random blood glucose $8.5 \mathrm{mmol} / \mathrm{l}$, serum ionized calcium $1.12 \mathrm{mmol} / \mathrm{l}$ (1.05 to $1.3 \mathrm{mmol} / \mathrm{l}$ ), and serum magnesium $0.8 \mathrm{mmol} / \mathrm{l}$ ( 0.75 to $0.95 \mathrm{mmol} / \mathrm{l})$. Her measured serum osmolality was $470 \mathrm{mOsm} / \mathrm{kg}$ with a urine osmolality of 280

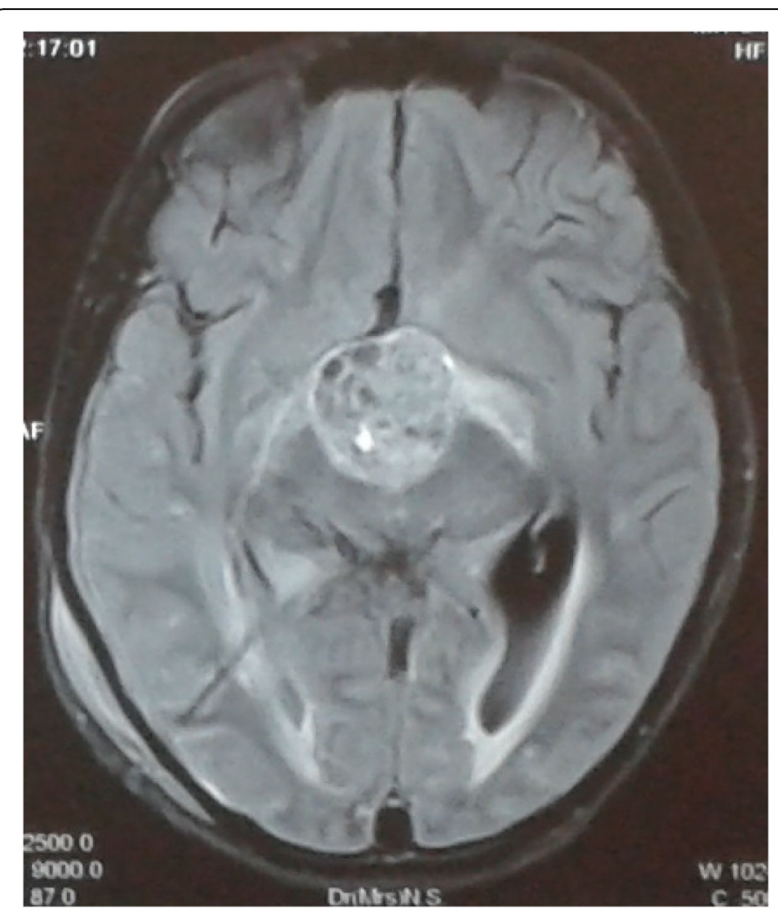

Fig. 1 Magnetic resonance imaging T1-weighted pre-contrast axial image showing suprasellar mass suggestive of craniopharyngioma

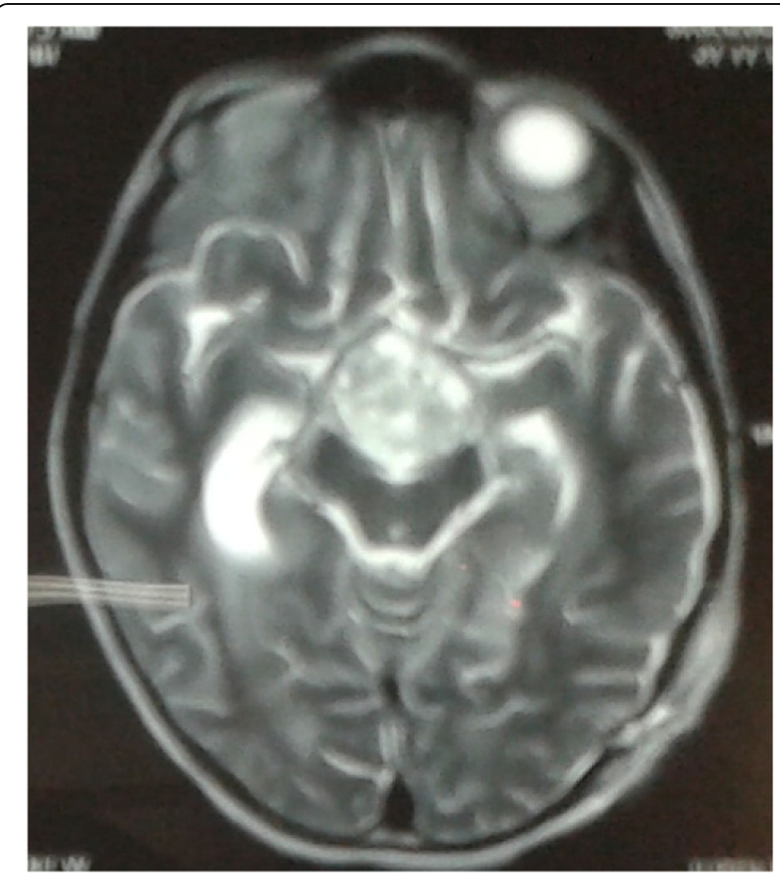

Fig. 2 Magnetic resonance imaging T2-weighted pre-contrast axial image of the lesion 


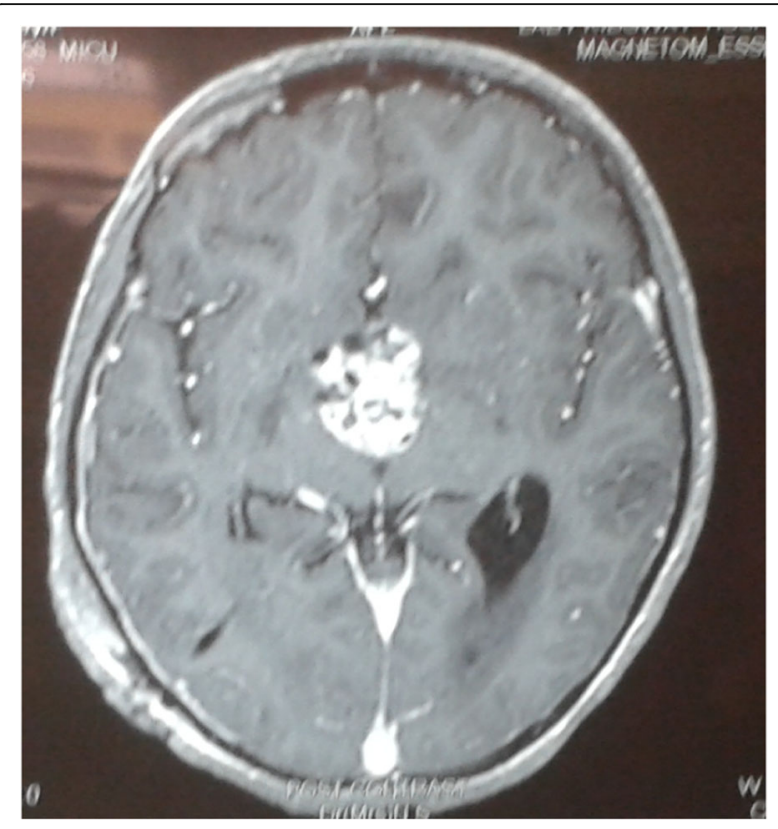

Fig. 3 Magnetic resonance imaging post-contrast axial image of the lesion

$\mathrm{mOsm} / \mathrm{kg}$. There was no discrepancy between measured and calculated serum osmolalities. Her urine spot sodium was elevated at $116 \mathrm{mmol} / \mathrm{l}$. A urine spot sodium of $>100 \mathrm{mmol} / \mathrm{l}$ can be seen in hypernatremia following ingestion of salt or infusion of $3 \%$ hypertonic saline. Considering the clinical and biochemical factors, hypernatremia in our patient can be attributed to infusion of $3 \%$ hypertonic saline in the background of cranial diabetes insipidus.

As we considered a sodium level of $226 \mathrm{mmol} / \mathrm{l}$ not compatible with life it was decided to correct her sodium levels rapidly. She was treated with an immediate dose of desmopressin 400 micrograms administered orally and hydrated with $5 \%$ dextrose administered intravenously and clear water via nasogastric feeding at a rate of $190 \mathrm{ml} /$ hour to replace the fluid deficit of 7 liters over 36 hours. Her polyuria settled and her serum sodium levels dropped to $160 \mathrm{mmol} / \mathrm{l}$ on the following day. However, her cardiac status became unstable and a 12lead ECG showed diffuse prolongation of QT intervals, ST depressions in leads V1 to V2, ST elevation in V3, and VT in V4 to V5 (Fig. 4). An urgent echocardiogram was planned but she developed VT and went into cardiac arrest. In spite of defibrillation and subsequent resuscitation she died.

\section{Discussion}

Hypernatremia defined as serum sodium levels >145 $\mathrm{mmol} / \mathrm{l}$, is associated with increased morbidity and mortality. Severe hypernatremia is defined as sodium levels $>160 \mathrm{mmol} / \mathrm{l}$ and extreme hypernatremia as >190 mmol/l.
Manifestations of hypernatremia vary from nonspecific central nervous system symptoms such as nausea, vomiting, muscle weakness, restlessness, irritability, and lethargy to confusion, nystagmus, seizures, myoclonic jerks, and even death. The level of consciousness is correlated with the severity of hypernatremia. Severe symptoms are likely to occur with acute increases in plasma sodium levels or at concentrations greater than $160 \mathrm{mmol} / \mathrm{l}$ [1]. Hypernatremia can cause brain shrinkage, resulting in vascular rupture and intracranial bleeding.

Cases of extreme hypernatremia in humans have been rarely reported and the literature describing ECG changes is scarce. Sodium is the most abundant extracellular cation and its current determines the depolarization and amplitude of the action potential. In Gibson and colleague's [4] study conducted on the effects of acute alterations in the blood sodium on ECG changes in dogs, rapid induction of hypernatremia showed QT prolongation and decrease in $\mathrm{P}$ and QRS amplitude as was seen in our patient. In Gibson and colleague's study [4], the reduction in the P and QRS amplitude were related to alterations in blood conductivity with a short circuiting effect on myocardial potentials. Prolongation of the QT interval is an indication of an increase in the duration of the action potential due to the high extracellular sodium levels causing an increase in the transmembrane gradient. In a further case of extreme hypernatremia in which a 29-year-old woman had serum sodium of $154 \mathrm{mmol} / \mathrm{l}$, ECG changes of sinus tachycardia, short PR interval, and diffuse ST depressions were observed [5]. A study performed by Fisher et al. [6] demonstrated that hypernatremia following acute subarachnoid hemorrhage was associated with adverse cardiac outcomes such as left ventricular contractile dysfunction, elevated cardiac enzymes, pulmonary edema, and death. The actual pathophysiology of hypernatremia on cardiac dysfunction is unknown. It is, however, hypothesized that increased extracellular sodium causes more calcium to exit the cell via sodium calcium exchanger on the sarcolemma. This results in reduced levels of intracellular calcium levels available for cardiac myocyte contraction causing a negative inotropic effect. Considering these facts, extreme hypernatremia would have been the most likely culprit for the fatal arrhythmia that occurred in our patient.

Our patient was given an infusion of $3 \%$ hypertonic saline in an attempt to reduce intracranial pressure. In the last decade many studies have been done on the effects of $3 \%$ hypertonic saline in intracranial pressure in traumatic or non-traumatic brain injury in experimental and human models [7, 8]. Side effects include rebound increased intracranial hypertension, renal impairment, subarachnoid hemorrhage, central pontine myelinolysis, high urinary water losses, and masking of diabetes insipidus. Further studies have shown that the prognosis in children with increased intracranial pressure having 


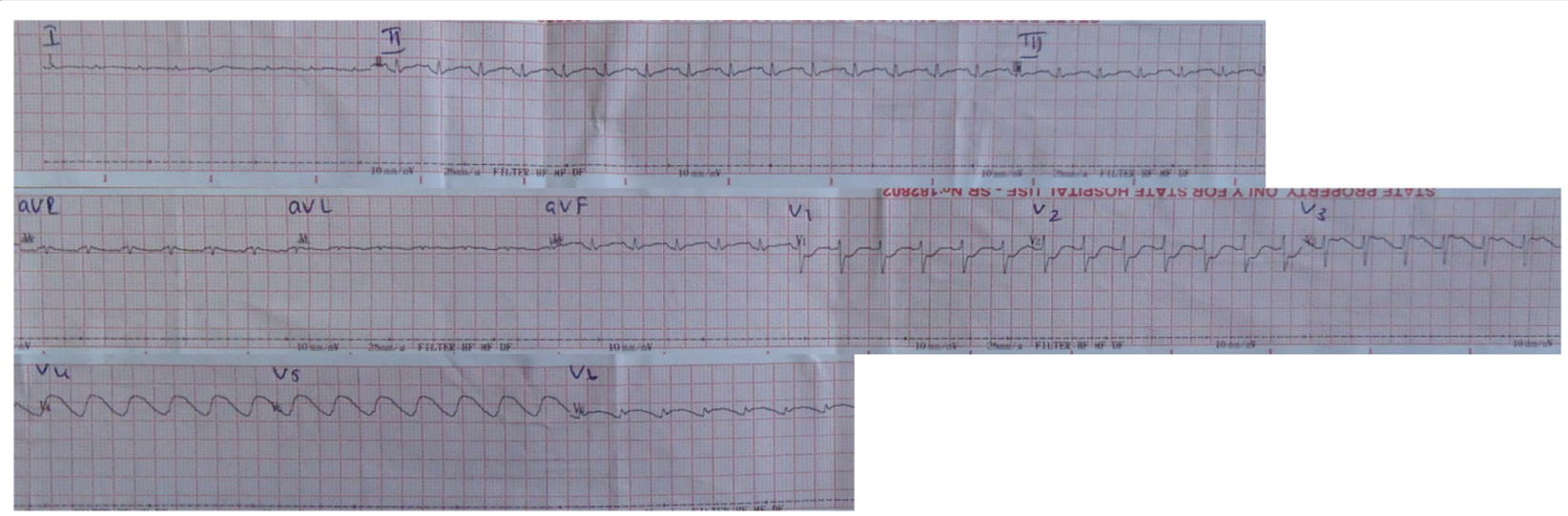

Fig. 4 Electrocardiogram showing tachycardia, small complexes, QT prolongation, ST segment deviations, and ventricular tachycardia in V4 and $\mathrm{V} 5$

higher levels of sodium within the range of 150 to 170 $\mathrm{mmol} / \mathrm{l}$ and higher levels of serum osmolality of 300 to $340 \mathrm{mOsm} / \mathrm{kg}$ appear to be better than normal to low levels of serum soidum and osmolality. However, no patient with a serum sodium $>180 \mathrm{mmol} / \mathrm{l}$ has had a good outcome [9]. There is Class II evidence supporting the use of hypertonic saline for the acute treatment of severe pediatric traumatic brain injury associated with increased intracranial hypertension and Class III evidence to support its use as a continuous infusion [10]. However, there are insufficient data to determine when to initiate, the duration of treatment, and target sodium concentrations. Further studies are required to resolve these concerns.

Management of such extreme cases of hypernatremia poses a therapeutic challenge. Hypernatremia initially causes fluid to move out of the brain leading to cerebral contraction causing alterations in mental status. To counteract this, the brain initially takes up electrolytes to reduce the contraction of cerebral volume. This is followed by a slower adaptive phase in which there is accumulation of organic osmolytes. Subsequently, the brain volume is restored as the solutes within the brain cells drag water into the cells and thereby restore the cerebral volume within 1 to 3 days [11]. When correcting hypernatremia, awareness regarding these acute and chronic stages is necessary as major changes in osmolality can eventually lead to cerebral edema.

Most literature published on the management of chronic hypernatremia recommends a slow correction rate of 10 to $12 \mathrm{mmol} / 24$ hours [2]. However, no prospective studies validate such recommendations. Alshayeb et al. carried out a study on correction rates in severe hypernatremia among hospitalized patients; they concluded that slower correction rates were associated with high mortality [3]. Cases published on extreme hypernatremia are scarce and the rate of correction and modes of correction differ. Most such cases with successful outcomes have achieved more rapid corrections without neurological sequelae [12-16]. A faster correction rate has a risk of causing cerebral edema and a slower rate will promote persistent hypernatremia. Both scenarios are associated with high mortality. However, in the cases with positive outcome, high correction rates were used based on the theory that extreme hypernatremia is not compatible with life. The therapeutic modes used to achieve these higher correction rates differ: fluid therapy, hemodialysis, and peritoneal dialysis.

In our patient, extreme hypernatremia (sodium level of $226 \mathrm{mmol} / \mathrm{l}$ ) was thought to be acute due to infusion of $3 \%$ hypertonic saline plus underlying cranial diabetes insipidus. Correction was done initially with clear water through nasogastric tube and $5 \%$ dextrose to achieve the fluid deficit of 7 liters during the first 36 hours. Her serum sodium dropped to $160 \mathrm{mmol} / \mathrm{l}$ on the following day and fluid replacement was changed to $0.45 \%$ normal saline with clear water at a lower rate. Several cases of extreme hypernatremia have been managed successfully with fluid therapy without any adverse neurological sequelae $[12,15]$. However, this was not the case in our patient who succumbed to a fatal arrhythmia. The rate of water replacement in severe hypernatremia is controversial and the available data are insufficient to enable consistent recommendations in such extreme cases.

Even though dialysis is not recommended in present guidelines on hypernatremia, it is believed to have a beneficial role in managing cases of acute extreme hypernatremia. Correction with fluid would require large volumes and longer duration, whereas with dialysis the duration of treatment can be curtailed. Furthermore, dialysis has beneficial effects in scenarios complicated with cardiopulmonary or renal disorders. The rate of correction can be adjusted by changing the concentration of sodium in the dialysate. Few cases of 
hypernatremia corrected with hemodialysis have been reported without any neurological complications despite the faster correction rate $[14,16]$. A safer approach in chronic hypernatremia would be continuous renal replacement therapy where sodium levels can be drawn every hour, and the fluid rate in addition to dialysate concentration can be changed easily [16]. Our patient was initially on inotropic support. However, with fluid resuscitation the inotropes were being gradually withdrawn. Whether she would have benefited from dialysis and, if so, from what form of dialysis, are questions to ponder on.

\section{Conclusions}

Extreme hypernatremia is a rare occurrence and literature on ECG changes in such patients is scarce. Our patient presented with acute extreme sodium levels of 226 $\mathrm{mmol} / \mathrm{l}$ following infusion with $3 \%$ hypertonic saline in an attempt to reduce intracranial pressure. Even though rapid correction of sodium was done via fluid therapy she developed fatal arrhythmias. ECG revealed gross diffuse QT prolongation with ST depressions and elevations which ultimately led to VT. This case highlights the rare ECG manifestations in extreme hypernatremia, controversies in target sodium levels when attempting to reduce intracranial pressure with hypertonic saline, and dilemmas in managing extreme hypernatremia.

\section{Abbreviations}

ECG: Electrocardiographic; VT: Ventricular tachycardia

\section{Acknowledgements}

We acknowledge the Neurosurgical Intensive Care Unit, National Hospital, Sri Lanka. Funding was not required for this study.

\section{Funding}

No funding was required for the reporting of this work.

\section{Availability of data and materials}

The datasets supporting the conclusions of this article are included within the article.

\section{Authors' contributions}

MHA was involved in acquisition of data and drafting the manuscript. NPS and CG participated in critically revising the manuscript and giving the final approval of the version to be published. All authors read and approved the final manuscript.

\section{Competing interests}

The authors declare that they have no competing interests.

\section{Consent for publication}

Written informed consent was obtained from the patient's legal guardian(s) for publication of this case report and any accompanying images. A copy of the written consent is available for review by the Editor-in-Chief of this journal.

\section{Ethics approval and consent to participate}

Not applicable.

Received: 24 May 2016 Accepted: 12 September 2016 Published online: 01 October 2016

\section{References}

1. Braun MM, Barstow CH, Pyzocha NJ. Diagnosing and management of sodium disorders: Hyponatremia and hypernatremia. Am Fam Physician. 2015;91(5):299-307.

2. Al-Absi A, Gosmanova EO, Wall BM. A Clinical Approach to the Treatment of Chronic Hypernatremia. Am J Kidney Dis. 2012;60(6):1032-8.

3. Alshayeb HM, Showkat A, Babar F, et al. Severe hypernatremia correction rate and mortality in hospitalized patients. Am JMed Sci. 2011;341(5):356-60

4. Gibson TC, Sugioka K, Sugioka M. The effect of acute alterations on blood sodium. J Electrocardiol. 1974;7(2):127-36.

5. Kazanji N, Assad WA, Gjeorgjiveski M, et al. Extreme hypernatremia (254 mmol/l) and electrocardiogram findings. Int Urol Nephrol. 2015;47:871-2.

6. Fisher LA, Ko N, Miss J, et al. Hypernatremia predicts adverse cardiovascular and neurological after SAH. Neurocrit Care. 2006;5(3):180-5.

7. Shackford SR, Bourgnignon PR, Wald SR, et al. Hypertonic saline resuscitation of patients with head injury: A prospective randomized clinical trial. J Trauma. 1998:44:50-8.

8. Qureshi Al, Suarez II. Use of hypertonic saline solutions in treatment of cerebral edema and intracranial hypertension. Crit Care Med. 2000;28:3301-13.

9. Peterson B, Khanna S, Fisher B, Marshall L. Prolonged hypernatremia controls elevated intracranial pressure in head-injured pediatric patients. Crit Care Med. 2000;28:1136-43.

10. Kochanek PM, Carney N, Adelson PD. Guidelines for acute medical management of severe traumatic brain injury in infants, children and adolescents. Paediatr Crit Care Med. 2012;13(1):Suppl 1:S1-82.

11. Lien YH, Shepiro Jl, Chan I. Effect of hypernatremia on organic brain osmoles. J Clin Invest. 1990;85:1427-36.

12. Park YJ, Kim YC, Kim MO, et al. Successful treatment in the patient with serum sodium level greater than 200 meq/l. J Korean Med Sci. 2000;15:701-3.

13. Borrego Dominguez RR, Imaz RA, Lopez-Herce CJ, Serina RC. Severe hypernatremia: survival without neurologic sequelae. Ann Pediatr. 2003;58: 376-80.

14. Yang TY, Chang JU, Tseng MH, et al. Extreme hypernatremia combined with rhabdomyolysis and acute renal failure. J Chin Med Assoc. 2009;72(10):555-8.

15. Lima EQ, Aguiar FC, Barbosa DM, et al. Severe hypernatremia, rhabdomyolysis and acute renal failure after cerebral aneurysm surgery. Nephrol Dial Transplant. 2004:19:2126-9.

16. Nur S, Khan Y, Nur S et al. Hypernatremia: Correction rates and hemodialysis. Case Rep Med. 2014, Article ID 736073. doi:10.1155/2014/ 736073.
Submit your next manuscript to BioMed Central and we will help you at every step:

- We accept pre-submission inquiries

- Our selector tool helps you to find the most relevant journal

- We provide round the clock customer support

- Convenient online submission

- Thorough peer review

- Inclusion in PubMed and all major indexing services

- Maximum visibility for your research

Submit your manuscript at www.biomedcentral.com/submit
C Biomed Central 